\title{
Stress AND BURNOUT IN A GROUP OF INTENSIVE CARE UNIT MEDICAL PERSONNEL - A PRELIMINARY STUDY
}

\author{
Jakub Lickiewicz $^{1 \mathrm{~A}, \mathrm{~B}, \mathrm{C}, \mathrm{D}, \mathrm{F}, \text { Barbara Salawa }}{ }^{2 \mathrm{~B}, \mathrm{D}}$, Wojciech Serednicki ${ }^{3 \mathrm{~B}, \mathrm{C}, \mathrm{D}, \mathrm{E}}$, Patricia Paulsen Hughes ${ }^{4 \mathrm{C}, \mathrm{D}, \mathrm{E}}$, Marta Makara $^{1 \mathrm{~F}}$
}

'Department of Health Psychology, Jagiellonian University Medical College, Cracow, Poland
'Faculty of Psychology, Pedagogy and Humanities, Andrzej Frycz Modrzewski Krakow University,
Cracow, Poland
${ }^{3}$ Intensive Care Unit, Jagiellonian University Medical College, Cracow, Poland
${ }^{4}$ Health and Human Performance, Oklahoma State University, United States
Authors' contribution:
A. Study design/planning • B. Data collection/entry • C. Data analysis/statistics • D. Data
interpretation • E. Preparation of manuscript • F. Literature analysis/search • G. Funds collection

\author{
Address for correspondence: \\ Dr Jakub Lickiewicz \\ Department of Health Psychology \\ Jagiellonian University Medical College \\ 25 Kopernika St., 31-501 Cracow, Poland \\ e-mail: jlickiewicz@cm-uj.krakow.pl \\ SUBMITTED: 02.04 .2021 \\ ACCEPTED: 25.07 .2021 \\ DOI: https://doi.org/10.5114/ppiel.2021.110451
}

\begin{abstract}
The aim of the study: Stress and burnout occur frequently among doctors and nurses. The goal of the work was to analyse differences in coping strategies and burnout between doctors and nurses in an intensive care unit.

Material and methods: The research was carried out in the intensive care unit of the Emergency Medicine Trauma and Disaster Centre of the University Hospital in Krakow, Poland. There were 119 participants: 37 male doctors, 23 female doctors, and 59 female nurses. The Maslach Burnout Inventory (MBI) and Mini-COPE Stress Management Inventory were used.

Results: Differences between medical doctors (MDs) in the level of burnout and coping strategies were found.

Conclusions: Interventions aimed at the welfare and psychological needs of health care professionals should be promptly implemented by hospital management, with a view to reducing psychological distress.

Key words: doctor, nurse, stress, burnout.
\end{abstract}

\section{INTRODUCTION}

Doctors and nurses are of interest to researchers studying stress and burnout [1]. Researchers have shown that doctors and nurses alike are tired and overburdened with work challenges, such as high patient load and ethical, medical, and legal responsibilities [2, 3]. Reported burnout levels have been reported to be often higher than 50\% [4-9]. Fatigue and overload are also characteristics of nurses whose burnout stems from socioeconomical factors, as well as hours of work, numbers of patients, job title, and level of education $[8,10,11]$.

Researchers see burnout as a serious problem and one of the greatest threats of the $21^{\text {st }}$ century in almost every work environment [12]. The causes of burnout are largely rooted in healthcare organisations and systems and include excessive workloads, inefficient work processes, office workloads, balancing home and work responsibilities, lack of organisational support, low professional status, and leadership. Individual factors also play a role, with higher burnout rates often being reported by women and younger doctors $[12,13]$. There is an established link between high levels of stress and subsequent burnout [14].

Research on stress shows that it is a predictor of burnout; therefore, the problems of burnout syn- drome are most often analysed from the point of view of stress theory, i.e. the long-term overload that results from continuous attempts to solve difficult situations, and to meet one's own expectations and environmental requirements [12].

According to Maslach [12], to describe the burnout syndrome, it is necessary to characterise 3 main elements, the first of which is emotional exhaustion. According to Maslach, the most stressful is the first of the symptoms of the burnout process, identified with excessive emotional strain due to the intensity of interpersonal contact. It manifests itself as discouragement from working, gradual decrease of interest and involvement in professional matters, reduced activity, and constant tension, leading to psychosomatic manifestations such as headaches, insomnia, and immune suppression, resulting in illness.

The second element of burnout is depersonalization, i.e. indifference and distancing from other people, superficiality, cynicism, and blaming others for failure. Depersonalisation, in other words, can be described as objectification, i.e. treating people/patients as cases and thus protecting themselves from involvement in relationships. This behaviour protects depleted personal emotional resources. Depersonalisation can be seen either as a way of dealing with emotional exhaustion or as a consequence of it. 
The third component is a reduced sense of personal achievement characterised by dissatisfaction with one's achievements, a sense of incompetence, a sense of being misunderstood, an inability to adapt to possible changes in the working environment, an inability to solve problems, conflict, and irritability. A reduced sense of personal achievement also refers to a loss of job satisfaction, blaming oneself for powerlessness, and low self-esteem. In extreme situations, aggressive reactions may be triggered, and escape reactions may also occur, such as frequent work absences [12].

\section{MATERIAL AND METHODS}

The aim of the study was to compare professional burnout in groups of male and female doctors, and female nurses, and related coping strategies. The study was conducted in the Department of Anaesthesiology and Intensive Care in the Emergency and Disaster Medicine Trauma Centre (CUMRiK) in Krakow. The study involved 119 participants employed in the Anaesthesiology and Intensive Care Unit.

The first tool used in the study was the Maslach Burnout Inventory (MBI) questionnaire, used to assess burnout syndrome $[15,16]$. The questionnaire consists of 22 items concerning feelings about one's profession. Each question is part of 1 of 3 separate subscales, which are emotional exhaustion, depersonalization, and sense of personal achievement. A high score on the subscale of emotional exhaustion and depersonalisation, and a low score in personal achievement indicates high burnout.

A second tool was Charles Carver's Mini-COPE questionnaire, adapted by Zygfryd Juczyński and Nina Ogińska-Bulik, containing 28 statements reflecting the response of respondents to stressful events, which measures the styles of dealing with stress (coping). The tool has been deemed reliable and accurate [17]. A 4-point scale is used, in which 0 means I almost never do so to 3 - I almost always do so. The scales are evaluated separately. The MiniCOPE tool is used to examine 14 strategies focused on the problem and on emotions, including: 1. Active coping, 2. Planning, 3. Positive re-evaluation (perceiving the problem in a more favourable light), 4. Acceptance, 5. Humour, 6. Religion, 7. Emotional support seeking, 8. Instrumental support seeking (looking for advice and help from others), 9. Substitute activities (dealing with other activities to divert attention from a difficult situation), 10. Denial, 11. Discharging, which is about revealing negative emotions, 12 . Substance use, 13. Stopping activities is interpreted as giving up efforts to improve the situation, and 14. Self-blaming [17].

Statistical analysis of the data was carried out using the Kruskal-Wallis test. The significance level for the test was set at $\alpha=0.05$.

\section{RESULTS}

The study involved 119 participants employed in the Anaesthesiology and Intensive Care Unit, including 37 male doctors (30.5\%), 23 female doctors (19.5\%), and 59 female nurses (50\%). The average age of the male physicians was $36.08 \pm 8.78$ years (25-56), for female physicians it was $37.96 \pm 7.49$ years (26-48), and for female nurses it was $34.53 \pm 8.12$ years (23-61).

Statistically significant differences in the assessment of personal achievement between a group of male doctors, female doctors, and nurses were shown $(p<0.001)$. According to post-hoc tests, statistically significant differences were found between the female physicians and nurses $(p=0.001)$ and between the male physicians and nurses $(p=0.008)$. The other $\mathrm{MBI}$ questionnaire scales did not differ significantly among the studied groups. The results are presented in Table 1.

Regarding the Mini-COPE questionnaire, statistically significant differences emerged in sense of humour among the male doctors, female doctors, and nurses $(p<0.001)$. According to the post-hoc tests, statistically significant differences were found between female medical doctors (MDs) and nurses $(p=0.011)$ and between female and male doctors $(p<0.001)$. Turn towards religion also differed significantly in the studied groups $(p=0.008)$, specifically between male doctors and nurses $(p=0.006)$.

Table 1. Descriptive statistics (mean, SD, median, range) and Kruskal-Wallis test on the Maslach Burnout Inventory (MBI) for male physicians, female physicians (MDs), and female nurses

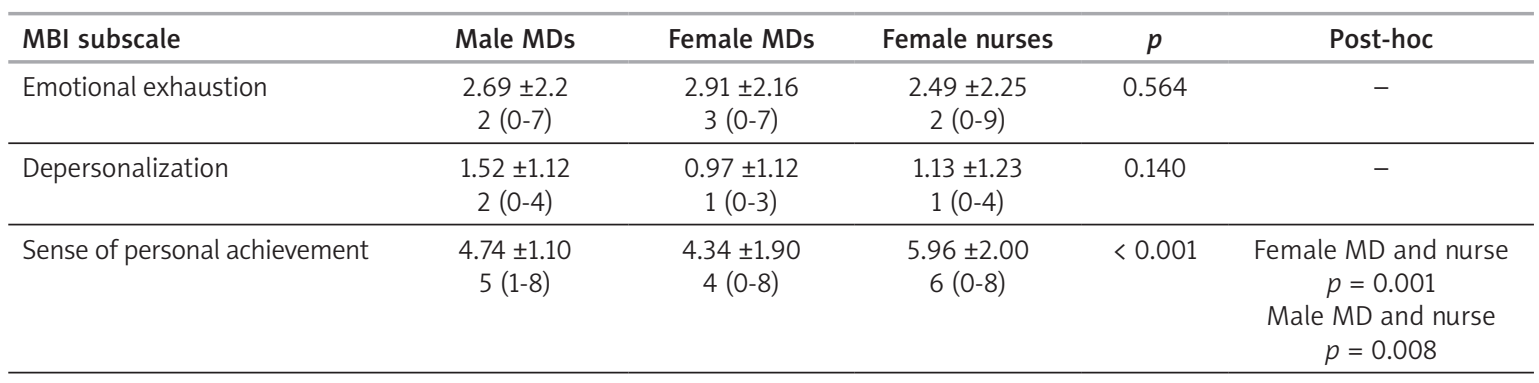


Table 2. Descriptive statistics (mean, SD, median, range) and Kruskal-Wallis test for the Mini-COPE scale for male physicians, female doctors (MDs), and female nurses

\begin{tabular}{|c|c|c|c|c|c|}
\hline Mini-COPE subscale & Male MDs & Female MDs & Female nurses & $p$ & Post-hoc \\
\hline Positive reframing & $\begin{array}{l}3.48 \pm 1.16 \\
4(1-6)\end{array}$ & $\begin{array}{l}3.22 \pm 1.45 \\
4(0-6)\end{array}$ & $\begin{array}{c}3.90 \pm 1.3 \\
4(1-6)\end{array}$ & 0.132 & - \\
\hline Acceptance & $\begin{array}{l}4.04 \pm 1.14 \\
4(1-6)\end{array}$ & $\begin{array}{l}3.61 \pm 1.40 \\
4(0-6)\end{array}$ & $\begin{array}{l}3.76 \pm 1.17 \\
4(0-6)\end{array}$ & 0.578 & - \\
\hline Sense of humour & $\begin{array}{l}2.30 \pm 1.06 \\
3(0-4)\end{array}$ & $\begin{array}{c}1.06 \pm 1.09 \\
3(0-4)\end{array}$ & $\begin{array}{l}1.86 \pm 1.33 \\
3(0-4)\end{array}$ & $<0.001$ & $\begin{array}{c}\text { Female MD and nurse } \\
\qquad \begin{array}{c}p=011 \\
\text { Female } M D \text { and male MD } \\
p<0.001\end{array}\end{array}$ \\
\hline Emotional support seeking & $\begin{array}{l}3.96 \pm 1.79 \\
4(0-6)\end{array}$ & $\begin{array}{c}4.08 \pm 1.48 \\
4(0-6)\end{array}$ & $\begin{array}{l}4.51 \pm 1.74 \\
5(1-6)\end{array}$ & 0.273 & - \\
\hline Instrumental support seeking & $\begin{array}{l}4.13 \pm 1.74 \\
5(1-6)\end{array}$ & $\begin{array}{l}3.94 \pm 1.45 \\
4(0-6)\end{array}$ & $\begin{array}{l}4.42 \pm 1.19 \\
4(2-6)\end{array}$ & 0.332 & - \\
\hline $\begin{array}{l}\text { Suppressing competing } \\
\text { activities }\end{array}$ & $\begin{array}{l}2.65 \pm 1.36 \\
3(0-5)\end{array}$ & $3.28 \pm 1.59$ & $\begin{array}{l}3.53 \pm 1.22 \\
4(1-6)\end{array}$ & 0.071 & - \\
\hline Denial & $\begin{array}{c}0.78 \pm 1.2 \\
0(0-4)\end{array}$ & $\begin{array}{c}0.81 \pm 0.82 \\
0(0-4)\end{array}$ & $\begin{array}{c}1.47 \pm 1.46 \\
0(0-4)\end{array}$ & 0.035 & $\begin{array}{l}\text { Male MD and nurse } \\
\qquad p=0.065\end{array}$ \\
\hline Venting & $\begin{array}{c}3.30 \pm 1.6 \\
4(0-6)\end{array}$ & $\begin{array}{l}2.67 \pm 1.14 \\
3(1-6)\end{array}$ & $\begin{array}{l}3.07 \pm 1.28 \\
3(1-6)\end{array}$ & 0.088 & - \\
\hline
\end{tabular}

The Kruskal-Wallis test showed statistically significant differences on denial among the three groups $(p=0.035)$. Post-hoc tests indicated a tendency for differences between male physicians and nurses, approaching statistical significance $(p=0.065)$. In the remaining scales of the Mini-COPE questionnaire, no statistically significant differences were found. Results are presented in Table 2 .

\section{DISCUSSION}

Statistically significant differences in professional burnout and coping strategies between doctors and nurses were shown. No such differences were found between male and female doctors, which indicates that it may be the function performed, rather than gender, from whence stemmed the differences. Gender has been found as a significant predictor of burnout among nurses in Iran [18], while in Romania, neither age nor sex were predictors of burnout among intensive care unit (ICU) staff $[19,20]$. In the present investigation, nurses showed a lower ability to deal with stressful situations than doctors. Occupational stress plays an important role in job burnout and quality of life among female nurses and female doctors, even after taking into account other potentially influencing factors [21].

In our research, the MDs scored higher on the burnout scale than nurses. However, this has not always been the case in previous studies [22, 23]. CUMRiK is a stressful place to work, with a lot of responsibility and a need for quick decisions for trauma patients.

Higher status healthcare workers like physicians and nurse practitioners are more likely than their colleagues to report work-life conflict, irregular work hours, and heavy work pressure. These stressors explain the higher levels of burnout found among physicians and nurse practitioners in the current study. In one Brazilian study, ICU nurses did not report high burnout [24], but Brazilian ICU doctors were highly stressed [25]. Collectively, our results lend support to "the stress of higher status" hypothesis and provide insights into the job demands and mental health issues confronted by today's medical workforce [26]. 
Our groups differed in their strategies for dealing with stress. Male doctors, more often than other groups, used humour as a way to relieve negative emotions. Female nurses, in turn, used this strategy more often than female doctors. At the same time, nurses more often sought emotional support in religion, and for them it was a way to reconcile difficult situations. Studies in Asia have confirmed the protective effect of religion among doctors and nurses [27]. Nurses in the present study often used denial, which is based on ignoring a stressful situation. However, in this case, it is a trend, not a statistically confirmed correlation.

\section{CONCLUSIONS}

The results show that there are differences in the level of burnout and coping strategies in the groups of doctors and nurses.

Thus, this may have serious consequences for the decisions made by medical staff, which will translate into the quality and effectiveness of treatment.

This may be related to the feeling of inferior education and perceived lower social status of nurses.

It is important to adopt different preventive measures to prevent burnout and improve quality of life among the 3 groups, according to different stressors [21]. Interventions aimed at addressing the welfare and psychological needs of health care professionals should be promptly implemented by the hospital management, with a view to reducing psychological distress [22]. It seems to be important to provide training and preventive programs in "mixed" groups of both physicians and nurses, which would positively influence coping strategies and would increase trust and team cohesion.

\section{Disclosure}

The authors declare no conflict of interest.

\section{References}

1. Vincent L, Brindley PG, Highfield J, et al. Burnout syndrome in UK intensive care unit staff: data from all three burnout syndrome domains and across professional groups, genders and ages. Journal of the Intensive Care Society 2019; 20: 363-369.

2. Hancock J, Hall R, Flowerdew G. Burnout in the intensive care unit: it's a team problem. Can J Anaesth 2019; 66: 472-473.

3. Macía-Rodríguez C, Iglesias DM, Diaz JM, et al. Burnout syndrome in internal medicine specialists and factors associated with its onset. Rev Clin Esp (Barc) 2020; 220: 331-338.

4. Bateman, ME, Hammer R, Byrne A, et al. Death Cafés for prevention of burnout in intensive care unit employees: study protocol for a randomized controlled trial (STOPTHEBURN). Trials 2020; 21: 1-9.

5. Hu Z, Wang H, Xie J et al. Burnout in ICU doctors and nurses in mainland China - a national cross-sectional study. J Crit Care 2021; 62: 265-270.

6. Elay G, Bahar I, Demirkiran H, Oksüz H. Severe burnout among critical care workers in Turkey. Saudi Med J 2019; 40: 943-948.
7. Vargas M, Spinelli G, Buonanno P, et al. Burnout among anesthesiologists and intensive care physicians: results from an Italian national survey. Inquiry 2020; 57: 0046958020919263.

8. Aragão NSCD, Barbosa GB, Santos CLC, et al. Burnout syndrome and associated factors in intensive care unit nurses. Rev Bras Enferm 2021; 74 (Suppl 3): e20190535.

9. Johnson-Coyle L, Opgenorth D, Bellows M, et al. Moral distress and burnout among cardiovascular surgery intensive care unit healthcare professionals: A prospective crosssectional survey. Can J Crit Care Nurs 2016; 27: 27-36.

10. Woo T, Ho R, Tang A, Tam W. Global prevalence of burnout symptoms among nurses: A systematic review and metaanalysis. J Psychiatr Res 2020; 123: 9-20.

11. Dyrbye LN, West CP, Johnson PO, et al. Burnout and satisfaction with work-life integration among nurses. J Occup Environ Med 2019; 61: 689-698.

12. Maslach C. Job burnout in professional and economic contexts. In: Ariyanto AA, Muluk H, Newcombe P, et al. (Eds.). Diversity in unity: Perspectives from psychology and behavioral sciences. Routledge/Taylor \& Francis Group 2018; 11-15.

13. West CP, Dyrbye LN, Shanafelt TD. Physician burnout: contributors, consequences and solutions. J Intern Med 2018; 283: 516-529.

14. Labrague LJ, McEnroe Petitte DM, et al. Organizational politics, nurses' stress, burnout levels, turnover intention and job satisfaction. Int Nurs Rev 2017; 64: 109-116.

15. Maslach C, Jackson SE, Leiter MP. MBI: Maslach burnout inventory. CPP, Incorporated, Sunnyvale, CA 1996.

16. Tucholska S. Christiny Maslach koncepcja wypalenia zawodowego: etapy rozwoju. Przegląd Psychologiczny 2001; 44: 301-317.

17. Juczyński Z, Ogińska-Bulik N. Narzędzia pomiaru stresu i radzenia sobie ze stresem. Pracownia Testów Psychologicznych, Warszawa 2009.

18. Rivaz M, Asadi F, Mansouri P. Assessment of the relationship between nurses' perception of ethical climate and job burnout in intensive care units. Invest Educ Enferm 2020; 38: e12.

19. Balan SA, Bubenek-Turconi Şı, Droc G, et al. Burnout syndrome in the Anaesthesia and Intensive Care Unit. Rom J Anaesth Intensive Care 2019; 26: 31-36.

20. Wu SY, Li HY, Wang XR, et al. A comparison of the effect of work stress on burnout and quality of life between female nurses and female doctors. Arch Environ Occup Health 2011; 66: 193-200.

21. Osifo JA, OlaOlorun FM, Asuzu MC. Job stress and psychological health of female doctors and nurses/midwives in selected tertiary hospitals in Ibadan. Nigeria IOSR J Dent Med Sci 2018; 17: 38-50.

22. Saravanabavan L, Sivakumar MN, Hisham M. Stress and burnout among intensive care unit healthcare professionals in an Indian tertiary care hospital. Indian J Crit Care Med 2019; 23: 462-466.

23. Vasconcelos EMD, Martino MMFD, França SPDS. Burnout and depressive symptoms in intensive care nurses: relationship analysis. Rev Bras Enferm 2018; 71: 135-141.

24. Tironi MOS, Teles JMM, Barros DDS, et al. Prevalence of burnout syndrome in intensivist doctors in five Brazilian capitals. Rev Bras Ter Intensiva 2016; 28: 270-277.

25. Grace MK, VanHeuvelen JS. Occupational variation in burnout among medical staff: evidence for the stress of higher status. Soc Sci Med 2019; 232: 199-208.

26. See KC, Zhao MY, Nakataki E, et al. Professional burnout among physicians and nurses in Asian intensive care units: a multinational survey. Intensive Care Med 2018; 44: 2079-2090. 